\title{
Transapical transcatheter aortic valve-in-valve implantation: Clinical and hemodynamic outcomes beyond 2 years
}

\author{
Jian Ye, MD, FRCSC, ${ }^{\mathrm{a}}$ John G. Webb, MD, ${ }^{\mathrm{b}}$ Anson Cheung, MD, ${ }^{\mathrm{a}} \mathrm{Jia}$ Lin Soon, MD, ${ }^{\mathrm{a}}$ David Wood, MD, ${ }^{\mathrm{b}}$ \\ Christopher R. Thompson, MD, ${ }^{\mathrm{b}}$ Brad Munt, MD, ${ }^{\mathrm{b}}$ Robert Moss, MD, ${ }^{\mathrm{b}}$ and \\ Samuel V. Lichtenstein, MD, $\mathrm{PhD}^{\mathrm{a}}$
}

\begin{abstract}
Objective: The feasibility of transapical valve-in-valve aortic valve implantation into a failed aortic surgical bioprosthesis has been confirmed. The purpose of the present study was to investigate the clinical and hemodynamic outcomes more than 2 years after transapical valve-in-valve aortic valve implantation.
\end{abstract}

\begin{abstract}
Methods: From April 2007 to May 2010, 8 consecutive patients underwent transapical valve-in-valve aortic valve implantation of either 23- or 26-mm Edwards-SAPIEN balloon-expandable bioprostheses into failed surgical tissue valves (21- to 25-mm valves). Clinical and echocardiographic follow-up was performed in all patients. The mean follow-up duration was $27.8 \pm 15.7$ months (range, 18-55 months).
\end{abstract}

\begin{abstract}
Results: Transapical valve-in-valve aortic valve implantation was successful in all patients (mean age, $84.1 \pm 1.6$ years). The predicted operative mortality was $42.1 \% \pm 15.7 \%$ by logistic European System for Cardiac Operative Risk Evaluation and $14.4 \% \pm 9.6 \%$ using the Society of Thoracic Surgeons risk calculator. The observed 30-day mortality was $12.5 \%$. No strokes or valve embolization/migrations occurred. The mean hospital stay was $9.0 \pm 9.1$ days. The New York Heart Association class decreased from preoperative class III-IV to postoperative class I in 6 of 7 survivors. The 2-year survival was $87.5 \%$. No late mortality occurred during the follow-up period. The echocardiographic results at 1 to 4 years of follow-up demonstrated stable valve position and function in all patients. The transaortic valve pressure gradients after valve-in-valve aortic valve implantation were greater than $20 \mathrm{~mm} \mathrm{Hg}$ and less than $15 \mathrm{~mm} \mathrm{Hg}$ in patients with 21- or 23-mm and 25-mm surgical valves, respectively.

Conclusions: Transapical valve-in-valve aortic valve implantation provides good clinical outcomes and stable valve function beyond 2 years of follow-up. The best hemodynamic and clinical outcomes can be achieved in the patients with a surgical valve size of $25 \mathrm{~mm}$ or greater. Valve-in-valve aortic valve implantation could become a viable approach for selected high-risk patients with failed surgical bioprostheses. (J Thorac Cardiovasc Surg 2013;145:1554-62)
\end{abstract}

Redo open-heart aortic valve replacement (AVR) remains the standard therapy for failed prosthetic valves. Redo isolated AVR carries a low risk of operative mortality and morbidity in most patients. However, bioprosthetic dysfunction or degeneration is more frequently observed in the elderly population, because bioprostheses are usually recommended in older patients. The risk of reoperative mortality and morbidity increases in elderly patients, ${ }^{1,2}$ particularly in those with comorbidities or patent coronary bypass grafts. Therefore, significant numbers of elderly patients

From the Division of Cardiac Surgery ${ }^{\mathrm{a}}$ and Division of Cardiology, ${ }^{\mathrm{b}}$ St. Paul's Hospital, University of British Columbia, Vancouver, British Columbia, Canada.

Disclosures: Drs Ye, Webb, Wood, Cheung, and Munt are consultants to Edwards Lifesciences. All other authors have nothing to disclose with regard to commercial support.

Received for publication March 4, 2012; revisions received April 12, 2012; accepted for publication May 9, 2012; available ahead of print June 14, 2012.

Address for reprints: Jian Ye, MD, FRCSC, Division of Cardiac Surgery, St. Paul's Hospital, 1081 Burrard St, Vancouver, BC V6Z 1Y6, Canada (E-mail: jye@ providencehealth.bc.ca).

0022-5223/\$36.00

Copyright (c) 2013 by The American Association for Thoracic Surgery doi:10.1016/j.jtcvs.2012.05.016 with degenerated bioprostheses are likely declined or not referred for redo AVR because of unacceptable operative mortality and morbidity. Recently minimally invasive transcatheter aortic valve implantation (AVI) has been demonstrated to be an alternative definitive therapy for patients with severe native aortic stenosis who would be at unacceptable high risk with conventional AVR ${ }^{3-11}$ The feasibility of transcatheter valve-in-valve implantation into failed surgical valves has been confirmed. We and others have reported the 30-day outcomes of transapical valve-in-valve AVI into failed surgically implanted bioprostheses. ${ }^{12-14}$ In the present study, we report the clinical and echocardiographic outcomes more than 2 years after transapical valve-in-valve AVI in patients with a mean follow-up of $27.8 \pm 15.7$ months, the longest follow-up for a case series.

\section{METHODS}

The procedures were approved by the Therapeutic Products Directorate, Department of Health and Welfare, Ottawa, Ontario, Canada, for compassionate clinical use in patients deemed not to be candidates for open heart surgery. 


\section{Abbreviations and Acronyms}

AVI = aortic valve implantation

AVR $=$ aortic valve replacement

NYHA $=$ New York Heart Association

TEE $=$ transesophageal echocardiography

\section{Patient Selection}

All patients with symptomatic failed bioprostheses were assessed independently by cardiologists and cardiac surgeons and accepted for the procedure on the consensus that conventional re-do AVR was excessively high risk in terms of anticipated mortality and morbidity. The European System for Cardiac Operative Risk Evaluation and Society of Thoracic Surgeons score were not used to determine the fitness for open-heart AVR. All patients provided written informed consent. From April 2007 to May 2010, 8 patients ( 2 women) underwent transapical transcatheter valve-invalve AVI of either 23- or 26-mm Edwards-SAPIEN balloon-expandable transcatheter valve into failed surgically implanted bioprostheses. The minimum follow-up period in the present case series was 18 months.

\section{Preoperative Preparation and Assessment}

Transthoracic echocardiography and diagnostic cardiac catheterization were a part of the routine preoperative evaluation. Transesophageal echocardiography (TEE) was performed to evaluate the bioprosthetic leaflet morphology or paravalvular regurgitation. The internal diameters of the surgical tissue valves in all patients, except for 1, were obtained from the information provided by the manufacturers. Important paravalvular leaks, endocarditis, and surgical valves that were too small were considered exclusions.

\section{Valve-in-Valve Implantation Technique}

The procedure for transapical transcatheter valve-in-valve AVI into a failed surgical bioprosthesis was quite similar to that for transapical AVI into a native aortic valve, which has been previously described in detail. ${ }^{6,15,16}$ In brief, the procedure was performed with the patient under general anesthesia in a hybrid operating room. Balloon valvuloplasty was not performed. Balloon-expandable transcatheter bioprostheses (Edwards SAPIEN transcatheter heart valve; Edwards Lifesciences, Irvine, Calif) for failed bioprostheses were used in our patients (Figure 1). Fluoroscopic and/or TEE imaging were sufficient for valve positioning. Intraoperative conventional aortography was not performed during valve positioning. For surgical valves with a radiopaque metal frame, optimal valve positioning mainly relied on the visualization of the region of the sewing cuff on fluoroscopy (Figure 2). For the valve without a radiopaque metal frame at the base (sewing cuff) of a bioprosthesis, valve positioning was performed with the assistance of TEE (Figure 3). Final positioning of the transcatheter valve was determined with rapid ventricular pacing before the deployment of a valve. Selection of the Edwards transcatheter valves for valve-in-valve implantation was determined by the estimated inner diameter of the failed surgical bioprostheses. All valve-in-valve procedures were performed without support of cardiopulmonary bypass. Postoperatively, the patients were instructed to take aspirin indefinitely and clopidogrel for at least 3 months. Warfarin was used if other indications were present, such as atrial fibrillation.

\section{Follow-up and Data Collection}

All patients were followed up by cardiac surgeons and clinical fellows. Follow-up included telephone interviews and office visits. The New York Heart Association (NYHA) class was assessed by either clinical fellows or staff surgeons. Follow-up echocardiography was performed either at our hospital or others and was read by the staff echocardiologists. The clinical follow-up and echocardiographic data were obtained before discharge, at 1,6 , and 12 months, and then yearly. The mean follow-up period was $27.8 \pm 15.7$ months (range, 18-55 months) with a total of 222 months of follow-up. Data were collected prospectively and presented as mean \pm standard deviation. The Valve Academic Research Consortium definitions were used. ${ }^{17}$

\section{RESULTS \\ Patients}

The mean patient age was $84.1 \pm 1.6$ years. The predicted perioperative mortality was $42.1 \% \pm 15.7 \%$ using the logistic European System for Cardiac Operative Risk Evaluation and $14.4 \% \pm 9.6 \%$ using the Society of Thoracic Surgeons risk calculator. Patients had various types of surgically implanted aortic bioprostheses, including the Carpentier-Edwards porcine valve (Edwards Lifesciences), Medtronic Mosaic valve (Medtronic, Minneapolis, Minn), Sorin Mitroflow pericardial valve (Sorin Group, Milan, Italy), and Ionescu-Shiley pericardial valve (Shiley Inc, Irvine, Calif). These surgical valves were implanted $13.6 \pm 7.0$ years (mean \pm standard deviation) before the valve-in-valve procedure. All patients presented with significant aortic stenosis, and 3 patients had concomitant severe aortic regurgitation. The baseline characteristics of the 8 patients are listed in Table 1 .

\section{Intraoperative Outcome}

The transcatheter valve was successfully implanted within the failed surgically implanted valve in all patients. All transcatheter valves were well seated in the surgical valves (Figure 2). One patient died on postoperative day 1. This patient had an Edwards SAPIEN 23-mm valve implanted inside a degenerated 21-mm Sorin Mitroflow pericardial aortic valve. Immediately after implantation it became apparent that a calcified leaflet of the failed bioprosthesis was obstructing the left main ostium (Figure 4). The patient died despite emergent conversion to openheart AVR. ${ }^{18}$

No other intraoperative complications, particularly no valve malpositioning, valve embolization, cardiac arrest, major arrhythmia, or apical bleeding were observed. The procedural characteristics are listed in Table 2.

\section{Clinical Outcomes}

Of the 7 survivors, 6 patients had excellent postoperative recovery and had no early complications. They were all discharged home. One patient had an uneventful operation and good early postoperative recovery, but he developed a perforation of a large sigmoid diverticulum on postoperative day 4. This patient underwent bowel surgery and was discharged on postoperative day 30 . The mean hospital stay was $9.0 \pm 9.1$ days (median, 6.5 days). No other early postoperative complications such as valve embolization/migration, postoperative bleeding, heart block or new pacemaker 


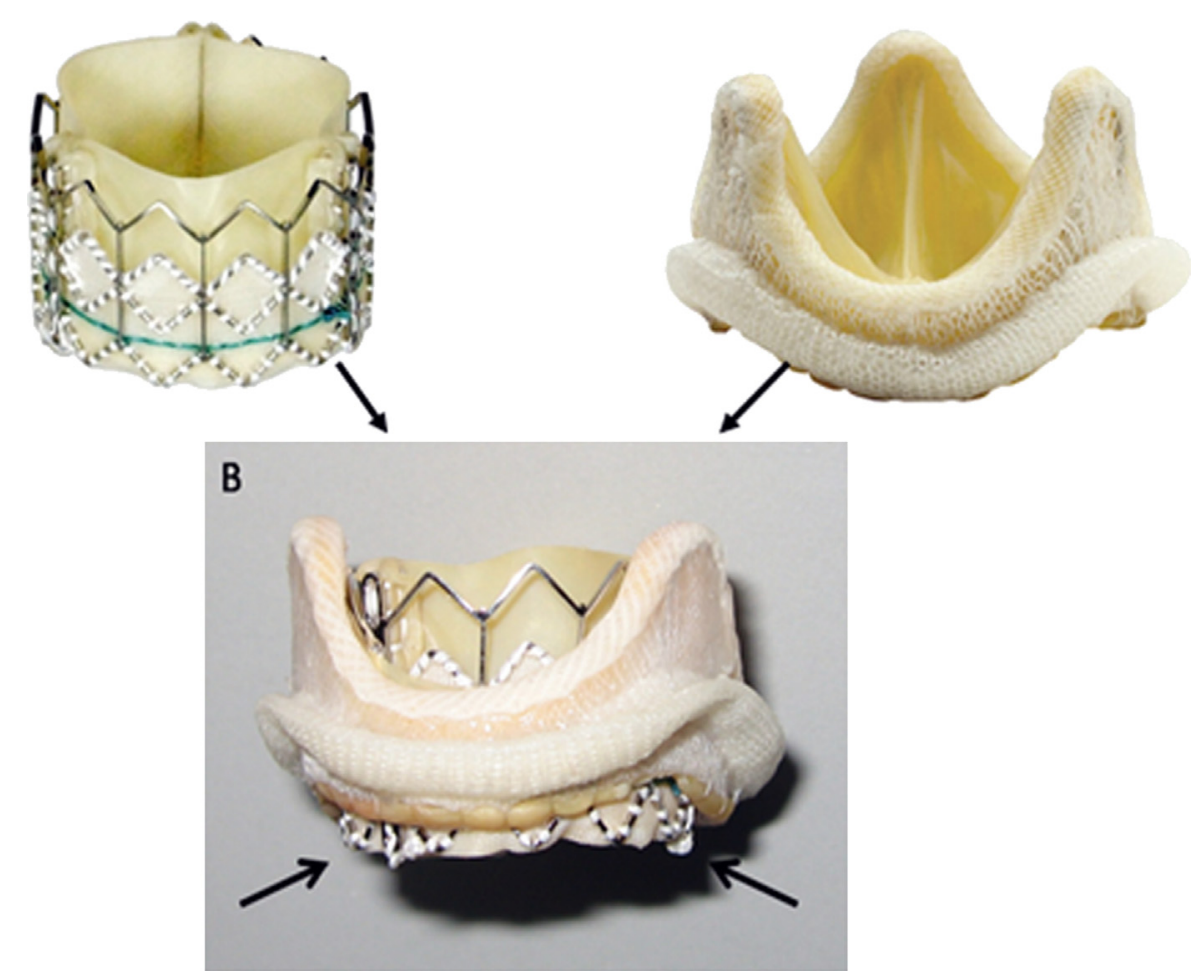

FIGURE 1. Balloon-expandable transcatheter bioprostheses and in vitro tests of valve-in-valve implantation.

implantation, pneumonia/sepsis, thromboembolic event/ stroke, or wound infection occurred (Table 2).

None of the remaining 7 patients had died at the last follow-up of 18 to 55 months. No valve-related complications, such as stroke or transient ischemic attack, myocardial infarction, major arrhythmia, endocarditis, thromboembolic events, or valve structural deterioration/ dysfunction, occurred during the follow-up period. Most patients experienced improvement in their symptoms and quality of life. In the 7 survivors, 6 patients had improvement in their heart failure symptoms (NYHA class), and 1 remained in NYHA class II-III because of pre-existing significant chronic obstructive pulmonary disease (Table 3). The 2-year survival was $87.5 \%$, and no late mortality occurred during the follow-up period.

\section{Echocardiographic Follow-up}

The predischarge transthoracic echocardiogram documented an increase in the estimated aortic valve area from $0.8 \pm 0.2 \mathrm{~cm}^{2}$ preoperatively to $1.1 \pm 0.5 \mathrm{~cm}^{2}$ and a reduction in the transaortic mean gradient from $39.1 \pm 11.0 \mathrm{~mm}$ $\mathrm{Hg}$ preoperatively to $27.5 \pm 12.2 \mathrm{~mm} \mathrm{Hg}$ postoperatively (Figure 5). The prosthetic valve area and transvalvular pressure gradient remained stable at 24 months of follow-up (Figure 5). The residual transaortic valve pressure gradient was relatively high (range, $23-48 \mathrm{~mm} \mathrm{Hg}$ ) when the transcatheter valve was implanted into $21-$ and $23-\mathrm{mm}$ surgical valves. In contrast, the mean pressure gradient was less than $15 \mathrm{~mm} \mathrm{Hg}$ (range, 11-13 $\mathrm{mm} \mathrm{Hg}$ ) when implanting into 25 -mm surgical tissue valves (Table 2). The mean pressure gradient in each patient at discharge and 1 year of follow-up is listed in Table 2 and Table 4, respectively. Follow-up echocardiography demonstrated good valve function in all patients up to 48 months. No prosthesis migration and no structural valve deterioration occurred. Valvular or paravalvular aortic insufficiency was determined by echocardiography. Six survivors had no paravalvular leak, and 1 patient had mild leakage at 12 months of follow-up (Table 4). Improvements in mitral regurgitation and tricuspid regurgitation were observed in 3 and 4 patients, respectively (Table 4).

\section{DISCUSSION}

The risk of operative mortality and morbidity increases in elderly patients who undergo reoperative AVR, although AVR remains the reference standard therapy for failed prosthetic valves. At our center, 286 patients underwent isolated repeat replacement of the aortic valve for prosthetic structural valve deterioration from 1975 to 1999 , with an overall operative mortality of $6.6 \% .{ }^{1}$ The mortality in patients with NYHA class IV was $16 \%$ and for those aged older than 70 years was $12.6 \%$. Eitz and colleagues ${ }^{2}$ reported a 30 -day mortality of $16.4 \%$ in patients aged 80 years and older undergoing reoperative AVR.

We performed the first transapical valve-in-valve AVI into a failed aortic surgical bioprosthesis in humans in 

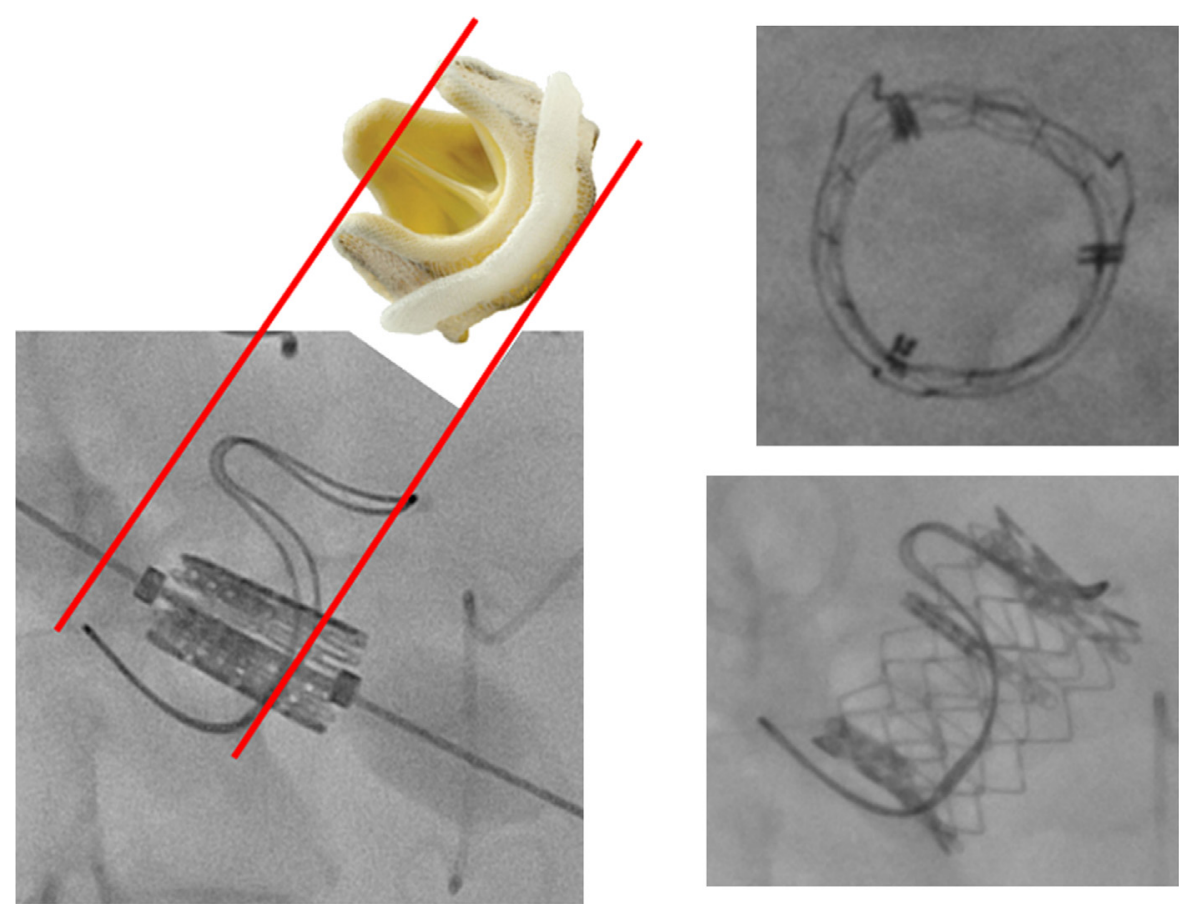

FIGURE 2. Transapical valve-in-valve implantation of a balloon-expandable transcatheter valve within a failed surgically implanted Edwards aortic bioprosthesis with a metal frame at the base.

2007. ${ }^{19}$ Since 2008 , many case reports ${ }^{19,20}$ and several case series $^{12-14}$ have been published of transcatheter valve-invalve implantation of either the CoreValve or Edwards SAPIEN valve into failed aortic surgical bioprostheses. These reports have demonstrated the feasibility and good early 30-day outcomes. Transcatheter valve-in-valve implantation with the Edwards valve is performed mainly using the transapical approach. The present study has summarized clinical and hemodynamic outcomes more than 2 years after transapical transcatheter valve-in-valve AVI. Our results have further confirmed the feasibility and safety of the valve-in-valve AVI and demonstrated good early clinical outcomes. More importantly, the present case series study has provided the longest clinical and

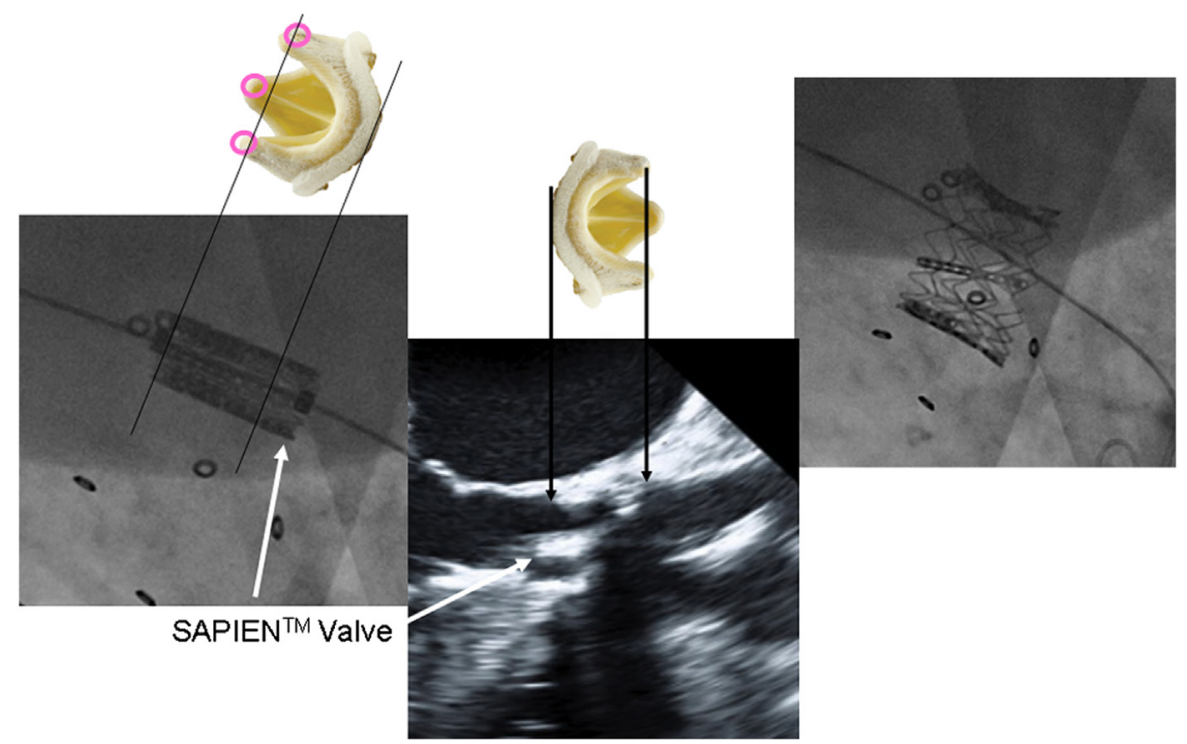

FIGURE 3. Transapical valve-in-valve implantation of a balloon-expandable transcatheter valve within a failed surgically implanted Medtronic Mosaic bioprosthesis without a metal frame at the base. 
TABLE 1. Baseline characteristics

\begin{tabular}{|c|c|c|}
\hline Characteristic & Patients (n) & Mean \pm SD or $\%$ \\
\hline Age (y) & 8 & $84.1 \pm 1.6$ \\
\hline Hypertension & 7 & $87.5 \%$ \\
\hline Diabetes & 1 & $12.5 \%$ \\
\hline Coronary artery disease & 7 & $87.5 \%$ \\
\hline Previous myocardial infarction & 5 & $62.5 \%$ \\
\hline Severe lung disease & 1 & $12.5 \%$ \\
\hline $\begin{array}{l}\text { Previous coronary artery bypass } \\
\text { grafting }\end{array}$ & 6 & $75.0 \%$ \\
\hline History of cerebral ischemic event & 0 & $0 \%$ \\
\hline Peripheral vascular disease & 5 & $62.5 \%$ \\
\hline History of gastrointestinal bleeding & 2 & $25.0 \%$ \\
\hline $\mathrm{eGFR}<60 \mathrm{~mL} / \mathrm{min}$ & 7 & $87.5 \%$ \\
\hline Ejection fraction $(\%)$ & 8 & $57.5 \pm 12.5$ \\
\hline Pulmonary hypertension ( $\mathrm{mm} \mathrm{Hg}$ ) & 8 & $48.5 \pm 14.7$ \\
\hline History of smoking & 7 & $87.5 \%$ \\
\hline Atrial fibrillation & 3 & $37.5 \%$ \\
\hline $\begin{array}{l}\text { Permanent pacemaker } \\
\text { euroSCORE }\end{array}$ & 1 & $12.5 \%$ \\
\hline Additive & 8 & $13.8 \pm 2.1$ \\
\hline Logistic & 8 & $42.1 \pm 15.7$ \\
\hline STS score & 8 & $14.4 \pm 9.6$ \\
\hline
\end{tabular}

SD, Standard deviation; euroSCORE, European System for Cardiac Operative Risk Evaluation; $e G F R$, estimated glomerular filtration rate; STS, Society of Thoracic Surgeons.

echocardiographic follow-up of transcatheter valve-invalve AVI.

\section{Survival and Clinical Outcomes During Follow-up}

It has been well documented that the average survival of patients with symptomatic aortic stenosis with congestive heart failure symptoms is approximately 2 to 3 years. Patients with symptomatic native aortic stenosis declined for surgery have a survival as low as $50 \%$ at 1 year and less than $25 \%$ at 2 years. ${ }^{10,21}$ In our study, the 1 -year survival was $87.5 \%$, with no additional mortality up to 4 years of follow-up. This suggests that transapical valve-in-valve AVI could improve survival in these extremely high-risk elderly patients who have symptomatic severe bioprosthetic stenosis/regurgitation. Transapical valve-in-valve AVI was also shown to provide symptomatic relief and quality of life improvement. Most survivors had NYHA class I heart failure symptoms after transapical valve-in-valve AVI. Also, most of the survivors were satisfied with their cardiac condition and were living independently at the last follow-up.

Early procedure-related complications and late valverelated complications, particularly stroke, were rare. No early or late valve displacement or embolization, no structural valve deterioration, and nonstructural valve dysfunction had developed at a follow-up of 4 years. Echocardiography demonstrated stable function of the balloonexpandable transcatheter bioprosthetic valves at up to 4 years of follow-up. However, longer term durability of the transcatheter tissue valve implanted into a surgical valve remains to be determined.

Six patients $(85.7 \%)$ had no paravalvular leakage during follow-up, suggesting that the incidence of paravalvular leaks might be lower after valve-in-valve implantation into a surgical valve than after transcatheter AVI into a native stenotic aortic valve. ${ }^{22}$ This was likely due to the more favorable sealing by the circular bioprosthetic valve frame/ stent and easy achievement of good positioning when a metal frame was visible at the base of the bioprosthetic valves.

As observed in patients undergoing transcatheter AVI for native aortic stenosis, patients with concomitant moderate to severe mitral or tricuspid regurgitation appeared to tolerate the transapical valve-in-valve AVI well

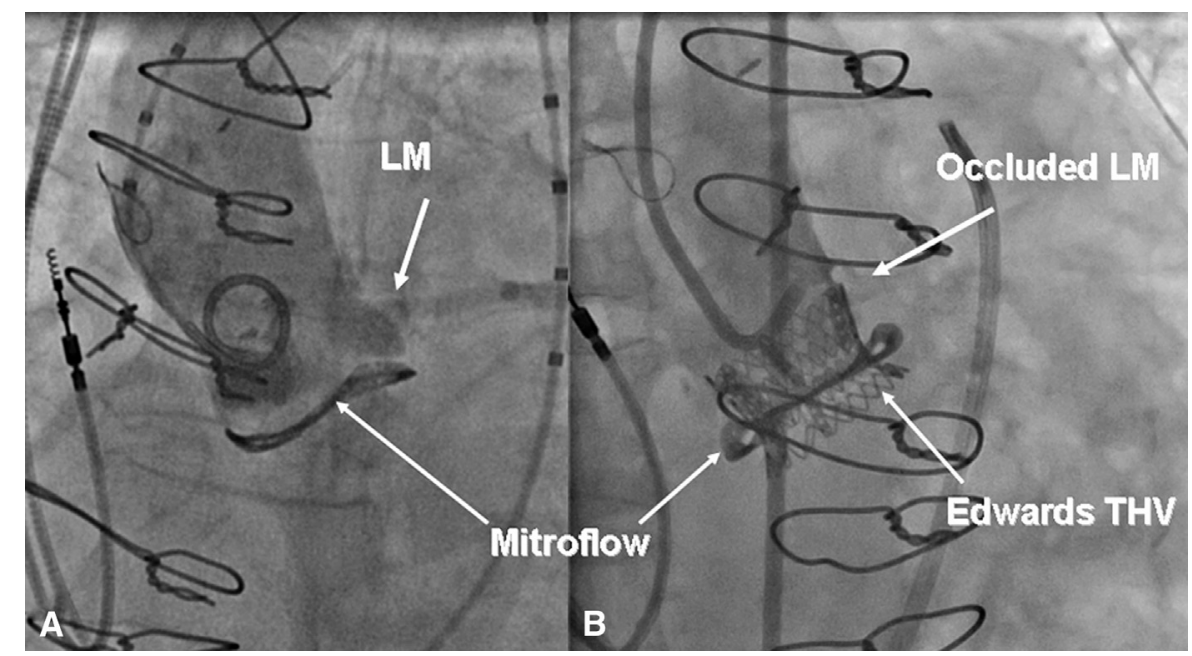

FIGURE 4. Left main obstruction after transapical valve-in-valve implantation into a failed Sorin Mitroflow aortic tissue valve. A, Small aortic root (a very "flat" sinus of Valsalva), a tightly fitted surgical valve, and low location of the left main ostium. B, Left main obstruction. $L M$, Left main (artery); THV, transcatheter heart value. 
TABLE 2. Procedure characteristics and early outcomes

\begin{tabular}{|c|c|c|c|c|c|c|c|c|}
\hline \multirow[b]{2}{*}{ Pt no. } & \multirow[b]{2}{*}{ Size and type of failed valve } & \multirow{2}{*}{$\begin{array}{l}\text { Valve pathologic } \\
\text { findings }\end{array}$} & \multirow{2}{*}{$\begin{array}{l}\text { Preoperative } \\
\text { MG }(\mathbf{m m} \mathrm{Hg})\end{array}$} & \multirow{2}{*}{$\begin{array}{c}\text { THV 9000TFX } \\
(\mathbf{m m})\end{array}$} & \multirow{2}{*}{$\begin{array}{l}\text { Intraoperative } \\
\text { complications }\end{array}$} & \multirow{2}{*}{$\begin{array}{c}\text { 30-d } \\
\text { Complications }\end{array}$} & \multicolumn{2}{|c|}{$\begin{array}{c}\text { Echocardiography } \\
\text { at discharge }\end{array}$} \\
\hline & & & & & & & AI & MG (mm Hg) \\
\hline 1 & 25-mm EC 2650 porcine & AI & 28 & 23 & No & No & 0 & 11 \\
\hline 2 & 23-mm EC 2650 porcine & $\mathrm{AI}+\mathrm{AS}$ & 31 & 23 & No & No & 0 & 24 \\
\hline 3 & 23-mm EC 2650 porcine & AS & 62 & 23 & No & No & 0 & 27 \\
\hline 4 & $\begin{array}{l}\text { 21-mm Ionescu-Shiley } \\
\text { pericardium }\end{array}$ & AS & 40 & 23 & No & No & Mild & 23 \\
\hline 5 & 25-mm EC 2650 porcine & AS & 38 & 26 & No & $\begin{array}{l}\text { Perforated } \\
\text { diverticulitis }\end{array}$ & 0 & 13 \\
\hline 6 & 21-mm Medtronic porcine & $\mathrm{AI}+\mathrm{AS}$ & 37 & 23 & No & $\begin{array}{l}\text { Left pleural } \\
\text { effusion }\end{array}$ & 0 & 48 \\
\hline 7 & $\begin{array}{l}\text { 21-mm Sorin Mitroflow } \\
\text { pericardium }\end{array}$ & AS & 48 & 23 & LM obstruction & Died on POD 1 & NA & NA \\
\hline 8 & $\begin{array}{l}\text { 23-mm Sorin Mitroflow } \\
\text { pericardium }\end{array}$ & AS & 38 & 23 & No & No & Mild & 32 \\
\hline
\end{tabular}

Pt no., Patient number; $M G$, mean gradient; $T H V$, transcatheter heart valve; $A I$, aortic insufficiency; $E C$, Edwards-Carpentier; $A S$, aortic stenosis; $L M$, left main; $P O D$, postoperative day; $N A$, not available.

intraoperatively. The mitral regurgitation remained unchanged or decreased, and tricuspid regurgitation usually improved after transapical valve-in-valve AVI (Table 4). This suggests that a conservative approach to coexisting mitral and tricuspid valve regurgitation could also be a reasonable approach for selected high-risk patients with failed aortic bioprostheses.

\section{Surgical Techniques and Complications}

Compared with transcatheter treatment of native aortic valve stenosis, valvuloplasty could conceivably be eliminated unless the bioprosthesis has critical stenosis, which would reduce a potential risk of stroke or embolic events. In this cohort of patients, the incidence of stroke after transapical valve-in-valve AVI appeared to be less than that in patients who underwent transapical AVI for native aortic stenosis. Theoretically, coronary ostial obstruction after valve-in-valve implantation is unlikely because a newly implanted transcatheter valve is deployed completely inside the frame of an old bioprothesis. However, a small aortic root (a very "flat" sinus of Valsalva), tightly fitted surgical valve, low location of the left main ostium (short distance

TABLE 3. Clinical follow-up

\begin{tabular}{|c|c|c|c|c|}
\hline \multirow[b]{2}{*}{ Pt no. } & \multirow{2}{*}{$\begin{array}{c}\text { Follow-up } \\
\text { duration }(\mathbf{m o})\end{array}$} & \multirow{2}{*}{$\begin{array}{c}\text { Survival } \\
\text { status }\end{array}$} & \multicolumn{2}{|c|}{ NYHA class } \\
\hline & & & Preoperatively & Postoperatively \\
\hline 1 & 55 & Yes & IV & I \\
\hline 2 & 35 & Yes & IV & I \\
\hline 3 & 33 & Yes & IV & I \\
\hline 4 & 32 & Yes & IV & I \\
\hline 5 & 25 & Yes & III (COPD) & II-III (COPD) \\
\hline 6 & 24 & Yes & IV & I \\
\hline 7 & 0 & No & IV & NA \\
\hline 8 & 18 & Yes & IV & I \\
\hline
\end{tabular}

from the aortic annulus), or globular calcification in a bioprosthetic cusp near the left main ostium are the potential risk factors for left main obstruction (Figure 4). The valve design with bioprosthetic cusps mounting outside the struts, such as the Sorin Mitroflow aortic valve, might increase a risk of left main obstruction, which was observed in 1 of our patients. However, this complication was not observed in other patients with Sorin Mitroflow aortic tissue valves who underwent transcatheter valve-in-valve AVI in our case series and others. ${ }^{13}$ We believe the location of the left main artery and the shape of the sinus of Valsalva are probably more important than the valve design itself. To avoid this significant complication, careful preoperative assessment of the aortic root is still important in patients undergoing the aortic valve-in-valve procedure.

\section{Positioning of Transcatheter Valves}

The anchoring site of bioprosthesis for the transcatheter valve is its sewing cuff, rather than its struts. Angiographic imaging should be in a plane perpendicular to the prosthesis to minimize foreshortening. It is critical that balloonexpandable transcatheter valves are positioned as coaxial as possible within a failed surgical prosthesis at deployment. In our experience, placing $25 \%$ to $30 \%$ of the SAPIEN valve upstream of the inflow aspect (ventricular side) of the bioprosthesis ensures that the fabric cuff of the transcatheter valve is positioned optimally in relation to the sewing ring of a surgical valve and provides both a very secure intravalvular fixation and minimizes paravalvular regurgitation (Figure 6). Rapid ventricular pacing might be required to determine optimal positioning if significant motion of a bioprosthesis occurs during the cardiac cycles. Aortography is not particularly helpful for positioning. Echocardiography is the primary imaging modality used to guide positioning if a surgical valve has 

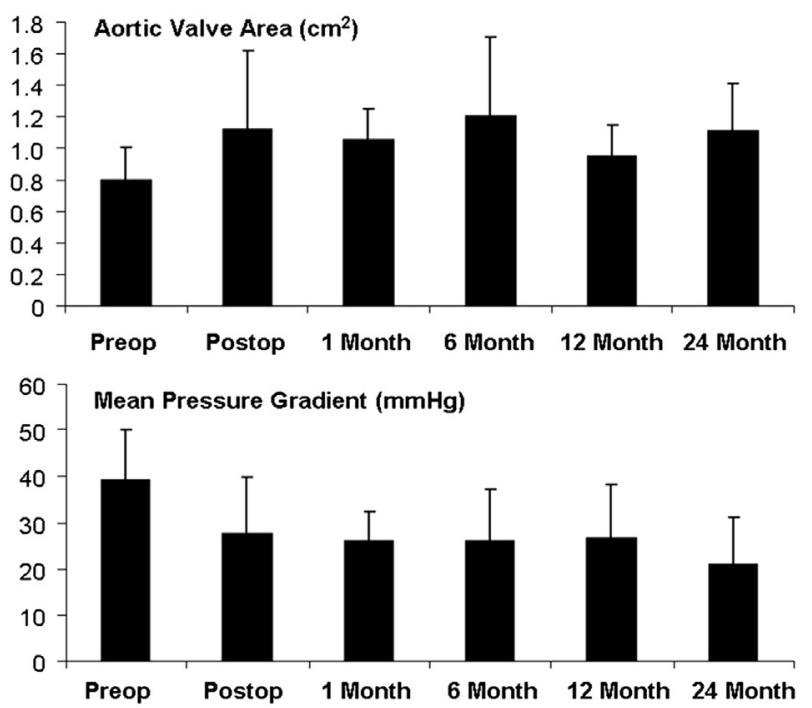

FIGURE 5. Echocardiographic follow-up on the aortic valve area and mean pressure gradient of Edwards SAPIEN valves implanted into failed surgical bioprostheses.

no radiopaque frame at its base, such as the Medtronic Mosaic tissue valve (Figure 5).

\section{Sizing Considerations}

The marketed size of bioprosthetic heart valves is typically described according to the external or metal frame diameter. However, the internal diameter of a surgical valve is more relevant for transcatheter valve selection. The internal diameter varies significantly by manufacturer and model, despite the same marketed size, and the internal diameter can still be misleading because no standardized reporting system is available. Moreover, the valve pathologic findings can also influence the selection of a transcatheter valve. The internal diameter of a failed bioprosthesis is usually not reduced if a bioprosthesis has severe regurgitation without significant calcification of its cusps; however, it might be smaller than its reported internal diameter if significant calcification and/or pannus is present. TEE (both 2-dimensional and 3-dimensional) and computed tomography might be helpful in the measurement of the internal diameter of a bioprosthesis.
Optimal transcatheter valve function requires full expansion to its nominal dimension. Ideally, the transcatheter valve would be only slightly larger than, or equivalent to, the internal diameter of the nonexpandable sewing cuff of a surgical bioprosthesis. If a transcatheter valve is too underexpanded, it can be expected to function suboptimally, with a high residual transvalvular pressure gradient and inappropriate leaflet coaptation, with likely reduced durability. The acceptable boundaries of underexpansion have not been defined. In our experience, patients with severe regurgitation can benefit from valve-in-valve implantation, despite underexpansion, with a significant residual pressure gradient. In contrast, a significantly underexpanded transcatheter valve might provide less clinical benefit to a patient with a stenotic bioprosthesis. For example, a 23-mm Edwards SAPIEN valve appears to result in acceptable hemodynamic performance when implanted within a $23-\mathrm{mm}$ bioprosthetic surgical valve with an internal diameter of approximately 19 to $20 \mathrm{~mm}$. Implantation of this transcatheter valve within a $21-\mathrm{mm}$ surgical valve is reasonable in patients, particularly those with severe bioprosthetic regurgitation, despite a high residual gradient. In the present case series, valve-in-valve implantation into $21-\mathrm{mm}$ surgical valves provides significant clinical benefits, regardless of the pathologic findings (aortic stenosis or aortic insufficiency) of the surgical valve. Although we do not have experience with 19-mm surgical valves, we believe implantation within a $19-\mathrm{mm}$ prosthesis is unlikely to be acceptable in a patient, particularly a patient with stenosis. In the present case series, the greatest mean pressure gradient was $48 \mathrm{~mm} \mathrm{Hg}$ in patient 6, who had a failed 21-mm Medtronic tissue valve. The reported internal stent diameter of the 21-mm Medtronic mosaic tissue valve is $18.5 \mathrm{~mm}$, smaller than that of the 21-mm Edwards or St. Jude Medical tissue valve. ${ }^{23}$ With a significant amount of the fabric cover, the true internal diameter is even smaller. We believe the high residual pressure gradient in this patient was likely due to the small internal diameter. High residual mean pressure gradients (range, $20-43 \mathrm{~mm} \mathrm{Hg}$ ) after implantation of either the SAPIEN valve or CoreValve into 21- or 23-mm surgical valves have also been reported by others. ${ }^{24,25}$ The high gradient after a valve-in-valve procedure is

TABLE 4. Echocardiographic follow-up at 1 year

\begin{tabular}{|c|c|c|c|c|c|c|c|c|c|c|}
\hline \multirow{2}{*}{$\begin{array}{r}\text { Pt } \\
\text { no. }\end{array}$} & \multicolumn{2}{|c|}{ MG (mm Hg) } & \multicolumn{2}{|c|}{ LVEF (\%) } & \multicolumn{2}{|c|}{ AI } & \multicolumn{2}{|c|}{ MR } & \multicolumn{2}{|c|}{ TR } \\
\hline & Preoperative & Postoperative & Preoperative & Postoperative & Preoperative & Postoperative & Preoperative & Postoperative & Preoperative & Postoperative \\
\hline 1 & 28 & 15 & 65 & 65 & Severe & No & Mild & Trivial & Mild & Trivial \\
\hline 2 & 31 & 18 & 35 & 45 & Severe & No & Moderate & Mild & Trivial & Trivial \\
\hline 3 & 62 & 27 & 45 & 45 & Trivial & No & Moderate & Mild & Moderate & Mild \\
\hline 4 & 40 & 20 & 65 & 65 & Mild & No & Mild & Mild & None & Trivial \\
\hline 5 & 38 & 11 & 60 & 65 & No & No & Mild & Mild & Trivial & Trivial \\
\hline 6 & 37 & 45 & 75 & 75 & Severe & No & Severe & Severe & Moderate & Mild \\
\hline 8 & 38 & 35 & 55 & 60 & Mild & Mild & Moderate & Moderate & Severe & Moderate \\
\hline
\end{tabular}

Pt no., Patient number; $M G$, mean gradient; $L V E F$, left ventricular ejection fraction; $A I$, aortic insufficiency; $M R$, mitral regurgitation; $T R$, tricuspid regurgitation. 


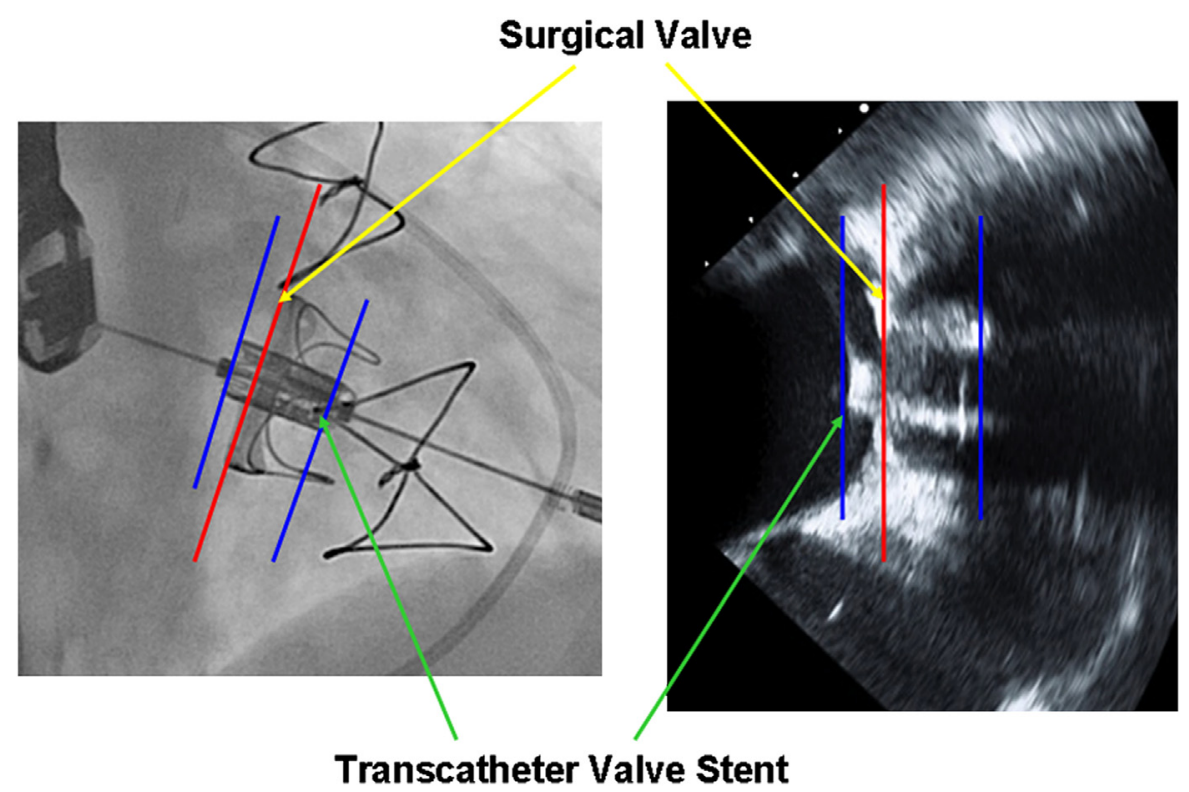

FIGURE 6. Appropriate positioning of a transcatheter valve within a surgical valve as determined by fluoroscopy or echocardiography.

concerning. For high-risk elderly patients with small surgical valves, high residual pressure gradients might reflect the use of valve-in-valve implantation as a palliative procedure. Thus, the valve-in-valve procedure should be only offered to elderly patients who are deemed to be too high risk to undergo re-do AVR. The potential of a future valve-in-valve option could be an additional reason for maximizing the size of an initial surgical valve ( $\geq 25 \mathrm{~mm}$ ), because our initial data have demonstrated that the residual transaortic pressure gradient is minimal $(<15 \mathrm{~mm} \mathrm{Hg})$ when a 23-mm SAPIEN valve is implanted within 25-mm surgical valves. The availability of various sizes of transcatheter valves and a standardized method of reporting the internal diameter of bioprostheses is desirable to expand this option. The feasibility of valve-in-valve AVI with either SAPIEN valve or CoreValve into failed stentless bioprostheses has also been reported; however, the experience is very limited. ${ }^{26,27}$

\section{Postoperative Anticoagulation}

It is our current management to give aspirin and clopidogrel to patients who undergo AVI into a native aortic valve. With up to 5 to 6 years of follow-up of these patients, stent valve thrombosis and valve-related thrombotic events, including stroke, have been very rare. In the present cohort of patients who underwent valve-in-valve AVI into failed surgical tissue valves, 5 patients were given aspirin indefinitely plus clopidogrel for at least 3 months, and 2 patients received aspirin plus warfarin for chronic atrial fibrillation. No stroke or embolic events were reported during the follow-up period, which might suggest that aspirin and clopidogrel are sufficient to prevent thrombosis. However, this needs to be evaluated clinically in a relatively large sample size.

\section{CONCLUSIONS}

Transapical valve-in-valve AVI of balloon-expandable valves into failed aortic surgical bioprostheses is safe with acceptable early mortality and morbidity. Transapical valve-in-valve AVI provides good clinical outcomes and stable valve function longer than 2 years of follow-up. The best hemodynamic and clinical outcomes can be achieved in patients with a surgical valve size of $25 \mathrm{~mm}$ or greater. Transapical valve-in-valve AVI might become a viable approach for selected high-risk patients with failed surgical bioprostheses. However, longer term follow-up is required before this method can be more broadly applied.

\section{References}

1. Jamieson WR, Burr LH, Miyagishima RT, Janusz MT, Frader GJ, Lichtenstein SV, et al. Re-operation for bioprosthetic aortic structural failurerisk assessment. Eur J Cardiothorac Surg. 2003;24:873-8.

2. Eitz T, Fritzsche D, Kleikamp G, Zittermann A, Horstkotte D, Körfer R. Reoperation of the aortic valve in octogenarians. Ann Thorac Surg. 2006;82:1385-91.

3. Webb JG, Chandavimol M, Thompson CR, Ricci DR, Carere RG, Munt BI, et al. Percutaneous aortic valve implantation retrograde from the femoral artery. Circulation. 2006;113:842-50.

4. Webb JG, Pasupati S, Humphries K, Thompson C, Altwegg L, Moss R, et al. Percutaneous transarterial aortic valve replacement in selected high-risk patients with aortic stenosis. Circulation. 2007;116:755-63.

5. Lichtenstein SV, Cheung A, Ye J, Thompson CR, Carere RG, Pasupati S, et al. Transapical transcatheter aortic valve implantation in humans: initial clinical experience. Circulation. 2006;114:591-6.

6. Ye J, Cheung A, Lichtenstein SV, Pasupati S, Carere RG, Thompson CR, et al. Six-month outcome of transapical transcatheter aortic valve implantation in the initial seven patients. Eur J Cardiothorac Surg. 2007;31:16-21.

7. Grube E, Schuler G, Buellesfeld L, Gerckens U, Linke A, Wenaweser P, et al Percutaneous aortic valve replacement for severe aortic stenosis in high-risk patients using the second- and current third-generation self-expanding CoreValve prosthesis: device success and 30-day clinical outcome. J Am Coll Cardiol. 2007;50:69-76.

8. Svensson LG, Dewey T, Kapadia S, Roselli EE, Stewart A, Williams M, et al. United States feasibility study of transcatheter insertion of a stented aortic valve by the left ventricular apex. Ann Thorac Surg. 2008;86:46-55. 
9. Rodés-Cabau J, Webb JG, Cheung A, Ye J, Dumont E, Feindel CM, et al. Transcatheter aortic valve implantation for the treatment of severe symptomatic aortic stenosis in patients at very high or prohibitive surgical risk: acute and late outcomes of the multicenter Canadian experience. J Am Coll Cardiol. 2010;55: 1080-90.

10. Leon MB, Smith CR, Mack M, Miller DC, Moses JW, Svensson LG, et al. Transcatheter aortic-valve implantation for aortic stenosis in patients who cannot undergo surgery. N Engl J Med. 2010;363:1597-607.

11. Smith CR, Leon MB, Mack MJ, Miller DC, Moses JW, Svensson LG, et al. Transcatheter versus surgical aortic-valve replacement in high-risk patients. $N$ Engl J Med. 2011;364:2187-98.

12. Webb JG, Wood DA, Ye J, Gurvitch R, Masson J-B, Rodés-Cabau J, et al. Transcatheter valve-in-valve implantation for failed bioprosthetic heart valves. Circulation. 2010;121:1848-57.

13. Kempfert J, Van Linden A, Linke A, Borger MA, Rastan A, Mukherjee C, et al. Transapical off-pump valve-n-valve implantation in patients with degenerated aortic xenografts. Ann Thorac Surg. 2010;89:1934-41.

14. Pasic M, Unbehaun A, Dreysse S, Buz S, Drews T, Kukucka M, et al. Transapical aortic valve implantation after previous aortic valve replacement: clinical proof of the "valve-in-valve" concept. J Thorac Cardiovasc Surg. 2011;142: 270-7.

15. Ye J, Cheung A, Lichtenstein SV, Carere RG, Thompson CR, Pasupati S, et al. Transapical aortic valve implantation in humans. J Thorac Cardiovasc Surg. 2006;131:1194-6.

16. Wong DR, Ye J, Cheung A, Webb JG, Carere RG, Lichtenstein SV. Technical considerations to avoid pitfalls during transapical aortic valve implantation. $J$ Thorac Cardiovasc Surg. 2010;140:196-202.

17. Leon MB, Piazza N, Nikolsky E, Blackstone EH, Cutlip DE, Kappetein AP, et al. Standardized endpoint definitions for transcatheter aortic valve implantation clinical trials: A consensus report from the Valve Academic Research Consortium. J Am Coll Cardiol. 2011;57:253-69.
18. Gurvitch R, Cheung A, Bedogni F, Webb JG. Coronary obstruction following transcatheter aortic valve-in-valve implantation for failed surgical bioprostheses. Catheter Cardiovasc Interv. 2011;77:439-44.

19. Ye J, Webb JG, Cheung A, Masson J-B, Carere RG, Thompson CR, et al. Transcatheter valve-in-valve implantation. 16 month follow-up. Ann Thorac Surg. 2009;88:1322-4.

20. Wenaweser P, Buellesfeld L, Gerckens U, Grube E. Percutaneous aortic valve replacement for severe aortic regurgitation in degenerated bioprosthesis: the first valve in valve procedure using the CoreValve revalving system. Catheter Cardiovasc Interv. 2007;70:760-4.

21. Kojodjojo P, Gohil N, Barker D, Youssefi P, Salukhe TV, Choong A, et al. Outcomes of elderly patients aged 80 and over with symptomatic, severe aortic stenosis: impact of patient's choice of refusing aortic valve replacement on survival. Q J Med. 2008;101:567-73.

22. Ye J, Cheung A, Lichtenstein SV, Thompson CR, Carere RG, Pasupati S, et al. Transapical transcatheter aortic valve implantation: follow-up to 3 years. $J$ Thorac Cardiovasc Surg. 2010;139:1107-13.

23. Gurvitch R, Cheung A, Ye J, Wood JA, Wilson AB, Toggweiler S, et al. Transcatheter valve-in-valve implantation for failed surgical bioprosthetic valves. $J$ Am Coll Cardiol. 2011;58:2196-209.

24. Eggebrecht H, Schafer U, Treede H, Boekstegers P, Babin-Ebell J, Ferrari M, et al. Valve-in-valve transcatheter aortic valve implantation for degenerated bioprosthetic heart valves. J Am Coll Cardiol Intv. 2011;4:1218-27.

25. Silva D, Stripling JH, Hansen L, Riess FC. Aortic valve replacement after transapical valve-in-valve implantation. Ann Thorac Surg. 2011;91:e5-7.

26. Rodes-Cabau J, Dumont E, Doyle D, Lemieux J. Transcatheter valve-in-valve implantation for the treatment of stentless aortic valve dysfunction. $J$ Thorac Cardiovasc Surg. 2010;140:246-8.

27. Attias D, Himbert D, Hvass U, Vahanian A. "Valve-in-valve" implantation in a patient with stentless bioprosthesis and severe intraprosthetic aortic regurgitation. J Thorac Cardiovasc Surg. 2009;138:1020-2. 